\title{
A literatura infantil brasileira do século XIX: indícios preliminares de fontes imediatas de Contos da carochinha, de Figueiredo Pimentel
}

Nineteenth-century Brazilian children's literature: preliminary evidence of immediate sources from Figueiredo Pimentel's Contos da Carochinha

\section{Cristina Rothier Duarte}

$\underline{\underline{\text { Daniela Maria Segabinazi }}}{ }^{2}$

1 Doutoranda do Programa de Pós-Graduação em Letras da Universidade Federal da Paraíba. E-mail: cristinarothier@hotmail.com.

2 Professora Doutora do Departamento de Letras e do Programa de Pós-Graduação em Letras da Universidade Federal da Paraíba. E-mail: dani.segabinazi@gmail.com. 
RESUMO: Neste artigo, apresentamos indícios de uma fonte imediata da adaptação de Figueiredo Pimentel, em Contos da carochinha (1894). De acordo com nossos estudos, verificamos que o autor brasileiro partiu da obra francesa L'Arbre de Noël (1873) para a escrita do primeiro volume da coleção Biblioteca Infantil da Livraria Quaresma, que inaugura cronologicamente a literatura infantil brasileira. Como objetivos deste trabalho, propomos a apresentação do autor francês, bem como a exposição de elementos preliminares que apontam L'Arbre de Noël como fonte de adaptação de Contos da carochinha.

PALAVRAS-CHAVE: Literatura Infantil Brasileira; Século XIX; Figueiredo Pimentel; Xavier Marmier.

ABSTRACT: In this article, we present evidence of an immediate source of Figueiredo Pimentel's adaptation, in Contos da carochinha (1894). According to our studies, we find that the Brazilian author started from the French book L'Arbre de Noël (1873) to write the first volume of the Livraria Infantil of Livraria Quaresma collection, which chronologically inaugurates the Brazilian children's literature. As objectives of this search, we propose the presentation of the French author, as well as the exposition of preliminary elements that point L'Arbre de Noë as a source of adaptation of Contos da carochinha.

KEYWORDS: Brazilian Children's Literature; 19th century; Figueiredo Pimentel; Xavier Marmier. 


\section{Introdução}

Ao ouvirmos falar em clássicos da literatura infantil, imediatamente, vêm-nos à mente os contos de fadas recolhidos e reunidos nas obras de Charles Perrault (16281703), de Jacob Ludwig Grimm (1785-1863) e Wilhelm Grimm (1786-1859), os Irmãos Grimm, e Hans Christian Andersen (1805-1875), sem nos atentarmos para o grande número de traduções e adaptações que se deram do trabalho dessas personalidades para cá. Por outro lado, sempre que nos remetemos ao estudo da história da literatura infantil brasileira e tratamos da importância de Figueiredo Pimentel (1869-1914), nesse cenário, especialistas como Zilberman (2016) e Arroyo (2011) são enfáticos em afirmar que as narrativas reunidas por esse autor sofreram um processo de reescrita (tradução e/ou adaptação), tomando como textos de partida obras de origem portuguesa e francesa, sem, contudo, apresentar alguma de suas fontes imediatas, afora as narrativas de origem na tradição oral.

Arroyo (2011), por exemplo, aponta que, segundo Luís da Câmara Cascudo, Figueiredo Pimentel, no seu processo de recolha das narrativas, não se dedicou a pesquisas diretas, mas tomou como textos de partida livros portugueses e franceses. Zilberman (2016, p. 37), por sua vez, informa que a coleção da Biblioteca Infantil, da Livraria Quaresma, encomendada a Figueiredo Pimentel, era "[...] formada a partir de recolha de narrativas então em circulação de preferência oral (ou em livros impressos em Portugal)." Como podemos observar, os estudiosos mostram uma direção, porém não nos indicam prováveis textos que serviram de inspiração para o trabalho do autor ora investigado.

Mesmo as informações trazidas nos prefácios das obras que publicou, compondo a Biblioteca Infantil, não são suficientes para deslindar a discussão, uma vez que apenas apresentam as fontes dos contos de forma genérica como o fez em Contos da Carochinha: "Lendo alguns dêles em francês, espanhol, italiano, alemão e inglês, colhendo outros diretamente da tradição oral, [Figueiredo Pimentel] contou-os a seu modo, em linguagem fácil, estilo correntio sem termos bombásticos e rebuscados, como convém, para o fim a que é a obra destinada." (QUARESMA [1894] /1958, p. 8); e no prefácio de Histórias da Avòzinha: "Na verdade aqui se encontram os mais célebres contos, dos que andavam 
apenas na tradição oral, e outros traduzidos de vários autores especialistas no assunto.” (QUARESMA, [1894] /1959, p. 6). ${ }^{3}$

No percurso de busca de fontes imediatas utilizadas por Figueiredo Pimentel para a publicação das obras infantis que organizou pela Livraria Quaresma, notamos semelhanças entre várias narrativas reunidas por esse autor, em Contos da Carochinha, e as publicadas pelo francês Xavier Marmier, em L'Arbre de Noël (1873), similitudes essas capazes de fazer-nos acreditar que, possivelmente, Figueiredo Pimentel operou sua reescrita partindo dos textos reunidos por esse autor. Sendo assim, neste artigo, apontamos os indícios preliminares que nos fizeram debruçar sobre um estudo comparativo das obras mencionadas.

\section{Xavier Marmier: fonte das adaptações de Figueiredo Pimen- tel na obra Contos da carochinba}

No cenário francês, é indubitável a importância de Perrault para a difusão dos contos de fadas, no entanto, tratando da influência que exerceu sobre a primeira obra literária infantil brasileira, Contos da carochinha, entra em cena a participação de um outro francês, Xavier Marmier (1808-1892), conforme demonstramos na seção seguinte deste trabalho. Antes, porém, trazemos uma breve apresentação desse autor, até o momento, pouco estudado, se não, ignorado.

De acordo com a Academie Française, ${ }^{4}$ romancista, poeta, viajante e tradutor de literaturas do norte europeu, que, nesta pesquisa, revela-se de suma importância, por acreditarmos ser uma de suas obras a fonte em que Figueiredo Pimentel bebeu para a reescrita de várias das narrativas reunidas em Contos da Carochinha ([1894]/1958).

Ainda, segundo a Academie Française, Xavier Marmier destacou-se entre os intelectuais de seu tempo, em razão da contribuição para o intercâmbio cultural entre a França e

3 Todas as citações de periódicos e de obras literárias seguem a ortografia original.

4 Disponível em: <http://www.academie-francaise.fr/les-immortels/xavier-marmier>. Acesso em: 02 jan. 2019. 
outros países do norte europeu (Islândia, Ilhas Faroe, Dinamarca, Noruega, Suécia, Finlândia, Holanda, Alemanha). Seu primeiro livro, publicado em 1830, foi Esboços poéticos. Conhecido pela numerosa quantidade de publicações frutos de suas viagens, em 1831, embarcou para uma incursão com destino a Leipzig, na Alemanha.

O site da Academie Française elenca 39 (trinta e nove) obras de sua autoria, entre elas: Pierre, ou les suites de l'ignorance (1833); Lettres sur l'Islande (1837); Langue et littérature islandaises. Histoire de l'Islande depuis sa découverte jusqu'à nos jours (1838); Histoire de la littérature en Danemark et en Suède (1839); Lettres sur le Nord - 2 vol. (1840); Souvenirs de voyages et traditions populaires (1841); Chants populaires du Nord. Lettres sur la Hollande (1842); Du Rhin au Nil Lettres sur l'Algérie - 2 vol. (1847); Voyage pittoresque en Allemagne- 2 vol (1858); En Amérique et en Europe (1859); De l'Est à l'Ouest, voyages et littérature (1867); Les États-Unis et le Canada. Récits américains. Trois jours de la vie d'une reine (1874); Au Sud et au Nord. Prose et vers (1890).

Consultando o site da Hemeroteca Digital Brasileira, localizamos alguns anúncios de obras de Xavier Marmier: Les voyages de Nils à la recherche de l'ideal; Littérature islandaise; Nouveaux Récites de Voyage, ${ }^{5}$ o que comprova que esse francês estava disponível para leitura no Brasil Oitocentista. Aqui, Xavier Marmier também foi traduzido e publicado em folhetim, no periódico fluminense $O$ Verdoense, ${ }^{6} \mathrm{com}$ a novela sueca $O$ destino d'uma andorinha. Na crônica Ver, ouvir e contar, assinada por Iriel e publicada no fornal do Commercio, o colaborador mencionou a importância desse escritor, porém esquecido por seus contemporâneos:

\footnotetext{
[...] Esse escriptor, tão profundamente ignorado da nossa geração, possue bastante bagagem litteraria, onde se encontrão romances intitulados [ilegível] ou os Perigos da Ignorância, mas onde tambem existe uma serie de Impressões de Viagem, absolutamente interessantes e que ainda hoje poderião ser lidas com prazer. Era, além disto, um fino espirito, um excellente caracter, um conversador incomparavel e um bibliômano sem rival (JORNAL DO COMMERCIO, ANO 70, n. 324, 20 nov, 1892, p. 1).
}

5 Os anúncios das obras mencionadas circularam no fornal do Commercio: ANO 63, n. 30, 29 out. 1885, p. 6; ANO 64, n. 16, 16 jan. 1886, p. 5; e ANO 69, n. 172, 22 jun. 1891, p. 7, respectivamente.

6 ANO IV, n. 20, 17 mai. 1885, p. 1-2. 
Sua morte também teve repercussão em nosso país, inclusive foi noticiada com uma breve biografia, em que se destacou a sua atividade como tradutor:

\footnotetext{
Dotado de uma aptidão verdadeiramente extraordinaria para o estudo das linguas, aprendeu a da maior parte dos paízes que visitou. Por meio de traducções de obras primas estrangeiras, estudos litterarios e descripções de viagens contribuiu para tornar conhecidas em França a litteratura, os costumes e a historia de varios paízes (JORNAL DO BRASIL, ANO II, n. 287, 14 out., 1892, p. 1).
}

Podemos perceber, diante do que circulava nos periódicos brasileiros, que, embora suas obras não fossem muito divulgadas aqui, Xavier Marmier não era um completo desconhecido nosso. Ademais, como mencionamos, Figueiredo Pimentel, em Contos da Carochinha ([1894]/1958), segundo nosso entendimento, teve como possível texto de partida L'Arbre de Noël (1873), obra em que o escritor francês reuniu 44 (quarenta e quatro) contos e lendas de origens diversas, que, segundo Cortez (2001), algumas foram traduzidas das obras: Deutsches Märchenbuch (1845), de Ludwig Bechstein (1801-1860), e Parabeln (1839), de Friedrich Adolf Krummacher (1767-1845).

Não somente Figueiredo Pimentel utilizou-se da obra de Xavier Marmier para a composição de seu trabalho, Guerra Junqueiro também partiu de contos de L'Arbre de Noël para a realização de Contos para a Infância, obra publicada pela primeira vez em 1877.

\section{L'Arbre de Noël: indícios de uma fonte imediata para narra- tivas reunidas em Contos da Carochinha}

Nesta seção, demonstramos os primeiros indícios que nos levam a crer na utilização de L'Arbre de Noël (1873), de Xavier Marmier, para a criação de narrativas presentes em Contos da carochinha.

7 Conforme Cortez (2001, p. 204), “[...] Marmier omite por completo o nome dos autores dos textos que integrou no seu volume, assim como os títulos das obras de onde foram retirados.” 
Mediante o cotejamento quantitativo entre os títulos dos contos presentes em L'Arbre de Noël (1873) e os reunidos em Contos da Carochinha (1958), percebemos que, dos 44 (quarenta e quatro) títulos em francês, 26 (vinte e seis) apresentam-se, de forma idêntica ou muito aproximada, na segunda obra: "João e Maria" e "Marguerite e Jean"; "Jacques e os seus companheiros" e "Jacques et ses camarades, conte irlandais"; "Os dois avarentos" e "Les deux avares, conte hébraïque"; "O Chapèuzinho Vermelho" e "L'histoire du petit chaperon rouge, comme on la raconte em Allemagne"; "O perigo da fortuna" e "Le péril de la fortune, légende alsacienne"; "A perseverança" e "Le succès de la persévérance, conte árabe"; "A justiça de Carlos Magno" (renomeado após a $1^{a}$ edição como "A gratidão da serpente") e "La justice de Charlemagne, légende suisse”; "A guarnição da fortaleza" e "La garnison de village, anedoctte historique"; "A briga difícil" e "La querele difficile"; "A gata borralheira" e "L'histoire de Cendrillon, comme on a la raconte em Allemagne"; "O tocador de violino" e "Le jouer de violon"; "O rei dos metais" e "Le roi des métaux"; "Branca como a neve" e "Blanche comme neige"; "O frade e o passarinho" e "Le moine et l'oiseau"; "O ratinho reconhecido" e "La souris reconnaissante"; "O anacoreta" e "L'anachorère, parabole de saint Jérome"; "Os três cães" e "Les trois chiens, conte allemand"; "O vaso de lágrimas" e "Le vase de larmes"; "Os meninos na mata" (renomeado após a 1 edição como "Os meninos vadios") e "Les enfants dans le bois, poésie allemande"; "Alice, a fina" (renomeado após a $1^{\text {a }}$ edição como "Berta, a esperta") e "La fine Alice, conte anglais"; "Os pêssegos" e "Les peches"; "O pé de feijão" e "Jacques et la tige de haricots, conte populaire anglais"; "Os dois caminhos" e "Les deux chemins, parabole allemande"; "O castelo de Kinast" e "Le châteux de Kynast, en Bohême"; "O irmão e a irmã" (renomeado após a $1^{\text {a }}$ edição como "O veadinho encantado") e "Le frère et la soeur”; e "Os infortúnios do alfaiate João" (renomeado após a $1^{\text {a }}$ edição como "Os caiporismos do alfaiate João") e "Les infortunes de Jean le tailleur, conte allemand".

Outro elemento comum entre as obras mencionadas, o qual nos faz crer, antes mesmo de partirmos para a leitura dos contos em francês, na possibilidade de Figueiredo Pimentel ter partido da obra de Xavier Marmier para o empreendimento da sua reescritura, são as gravuras. Das 68 (sessenta e oito) que ilustram L'Arbre de Noël, 58 (cinquenta e oito) inspiraram o autor das imagens contidas em Contos da Carochinha, tendo em vista que, comparando ilustrações da obra de Xavier Marmier com as suas correspondentes em Figueiredo Pimentel, notamos 
muitas semelhanças nos elementos e nos detalhes, embora seja perceptível que não se trata de duplicação idêntica (reprodução).

Para exemplificar, nas Figuras 1 e 2, temos, respectivamente, as gravuras que ilustram "L'histoire du petit chaperon rouge", de Xavier Marmier, e "O Chapèuzinho Vermelho", de Figueiredo Pimentel. A duas apresentam os mesmos elementos: a menina, o lobo e a floresta, além de detalhes tais como: a menina, nas duas ilustrações, estão com postura idêntica em relação ao lobo, os braços posicionados da mesma maneira e o chapéu aparenta ser de modelo semelhante. O que afasta uma ilustração da outra é a situação dos elementos. Enquanto a menina está à direita do lobo na primeira ilustração (Figura 1), ela aparece à esquerda do animal na segunda (Figura 2), como se um desenho fosse o reflexo do outro. Essa estratégia empregada para a diferenciação entre as imagens foi usada em todas as gravuras contidas em Contos da Carochinha (1958), inspiradas nas de L'Arbre de Noël (1873). As gravuras, ainda, diferenciam-se pelo traço do desenho e pela assinatura do(s) ilustrador(es), indícios que nos fazem concluir que não foram realizadas pelos mesmos artistas. ${ }^{8}$

8 As gravuras de Contos da Carochinha não foram assinadas. Já a capa da obra de Xavier Marmier apresenta como graveur de L'Arbre de Noël (1873) Bertall (1820-1882), embora tenha encontrado também as assinaturas de Jean Gauchard (1825-1872), e Charles Laplante (1837-1903). 


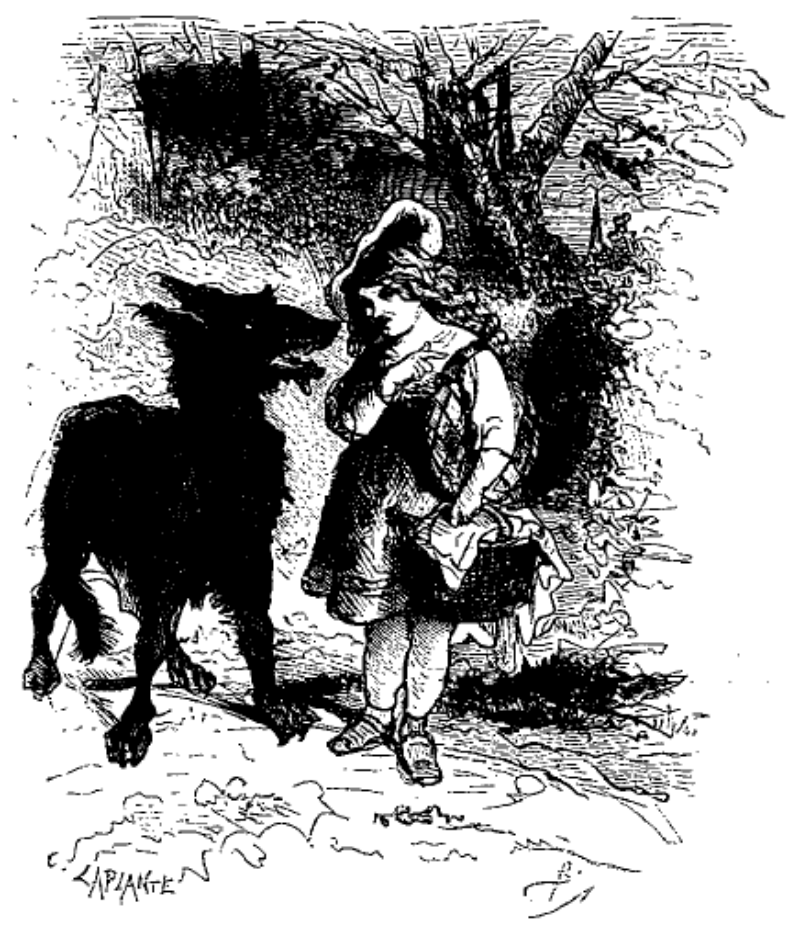

Figura I - Ilustração de "L'histoire du petit chaperon rouge"

Fonte: MARMIER (1873).

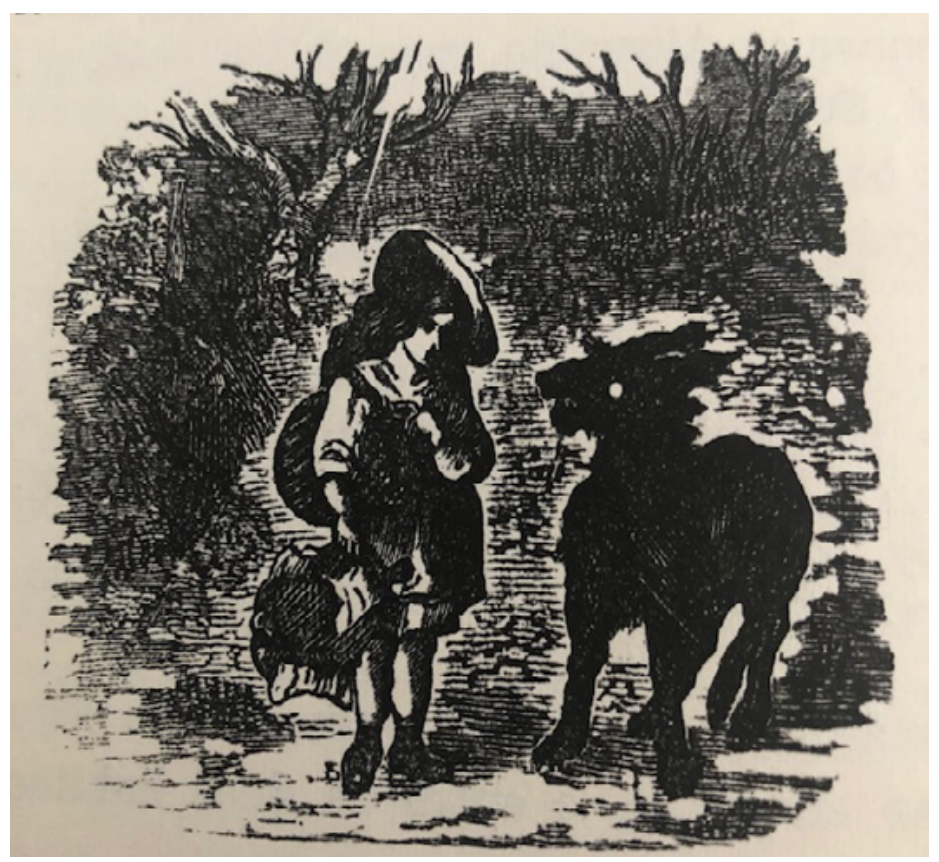

Figura 2 - Ilustração de "O Chapèuzinho Vermelho"

Fonte: PIMENTEL (1958). 
Em investigações sobre textos de partida utilizados na reescrita de uma obra que não apresenta informações suficientes sobre autoria, entendemos que o simples fato de essa apresentar igualdade ou semelhança, quanto aos títulos de narrativas reunidas e quanto às ilustrações contidas em outra obra, não significa, peremptoriamente, que uma seja o texto-fonte da outra. $\mathrm{Na}$ tentativa de comprovar essa relação derivativa, precisamos ir além, fazendo-se necessária a leitura desse possível texto de partida, a fim de efetuarmos uma análise comparativa que, ao final, apresente dados justificadores de sua utilização em uma dada reescrita.

Desse modo, após a leitura de L'Arbre de Noël (1873), identificamos 34 (trinta e quatro) contos a partir dos quais Figueiredo Pimentel realizou a reescritura das seguintes narrativas que compõem Contos da Carochinha (1958): ${ }^{9}$

9 Contos reunidos por Xavier Marmier não reescritos por Figueiredo Pimentel em Contos da Carochinha (1958): "L'ambitieux sapin”, "Le Chardonneret el l'Ovrier, histoire canadienne”; "Chant d'une mère près du berceau de son enfant, poésie finlandaise"; "La création de l'homme, légende des Peaux Rouges de l'Amérique du nord", "La chanson du gazon, poésie américaine", "Souvenir d'enfance, poésie danoise, par Baggesen”, "Le château de la chaumière, poésie suédoise”, "La vouivre, légende francomtoise", "La légende de la Sarraz", "Florella, conte américan". 


\begin{tabular}{|c|c|}
\hline $\begin{array}{l}\text { L'ARBRE DE NOËL, CONTES DE LE- } \\
\text { GENDES, DE XAVIER MARMIER (I873) }\end{array}$ & $\begin{array}{l}\text { CONTOS DA CAROCHINHA, DE } \\
\text { FIGUEIREDO PIMENTEL (I958) }\end{array}$ \\
\hline Marguerite et Jean & João e Maria \\
\hline Jacques et ses camarades, conte irlandais & Jacques e os seus companheiros \\
\hline Les deux avares, conte hébraïque & Os dois avarentos \\
\hline $\begin{array}{l}\text { L'histoire du petit chaperon rouge, comme on } \\
\text { la raconte em Allemagne }\end{array}$ & O Chapeuzinho Vermelho \\
\hline Le péril de la fortune, légende alsacienne & O perigo da fortuna \\
\hline Les trois dons de l'ermite, conte allemand & A velhinha da floresta \\
\hline Le succès de la persévérance, conte árabe & A perseverança \\
\hline La justice de Charlemagne, légende suisse & $\begin{array}{l}\text { A gratidão da serpente (A justiça de Car- } \\
\text { los Magno, 1894). }\end{array}$ \\
\hline La garnison de village, anedoctte historique & A guarnição da fortaleza \\
\hline La querele difficile & A briga difícil \\
\hline $\begin{array}{l}\text { L'histoire de Cendrillon, comme on a la ra- } \\
\text { conte em Allemagne }\end{array}$ & A Gata Borralheira \\
\hline Le jouer de violon & O tocador de violino \\
\hline Le roi des métaux & O rei dos metais \\
\hline Le piex rabbin, légende hébraïque & $\begin{array}{l}\text { O solitário da cabana (O rabino piedoso, } \\
1894)\end{array}$ \\
\hline L'église de Falster & A igreja de Falster \\
\hline La cathédrale du roi & A igreja do rei \\
\hline La légende de la Blusmisalpe, em Suisse & A lenda da montanha \\
\hline Blanche comme neige & Branca como a neve \\
\hline Le moine et l'oiseau & O frade e o passarinho \\
\hline Christophe le malin, conte irlandês & João Bobo \\
\hline La souris reconnaissante & O ratinho reconhecido \\
\hline L'anachorère, parabole de saint Jérome & O anacoreta \\
\hline Les trois chiens, conte allemand & Os três cães \\
\hline Le vase de larmes & O vaso de lágrimas \\
\hline Tom Pouce, conte populaire anglais & O Pequeno Polegar \\
\hline Les enfants dans le bois, poésie allemande & $\begin{array}{l}\text { Os meninos vadios (Os meninos na mata, } \\
1894 \text { ) }\end{array}$ \\
\hline Le rouge-gorge & O canário (O pintassilgo, 1894) \\
\hline La fine Alice, conte anglais & Berta, a Esperta (Alice, a fina, 1894) \\
\hline Les peches & Os pêssegos \\
\hline $\begin{array}{l}\text { Jacques et la tige de haricots, conte populaire } \\
\text { anglais }\end{array}$ & O pé de feijão \\
\hline Les deux chemins, parabole allemande & Os dois caminhos \\
\hline Le châteux de Kynast, en Bohême & O castelo de Kinast \\
\hline
\end{tabular}




\begin{tabular}{|l|l|}
\hline Le frère et la soeur & $\begin{array}{l}\text { O veadinho encantado (O irmão e a ir- } \\
\text { mão, 1894) }\end{array}$ \\
\hline $\begin{array}{l}\text { Les infortunes de Jean le tailleur, conte alle- } \\
\text { mand }\end{array}$ & $\begin{array}{l}\text { Os caiporismos do alfaiate João (Os in- } \\
\text { fortúnios do alfaiate João, 1894) }\end{array}$ \\
\hline
\end{tabular}

Quadro I - Contos correspondentes em Xavier Marmier e Figueiredo Pimentel Fonte: Elaborado pela autora.

\section{Considerações finais}

Neste artigo, apresentamos brevemente Xavier Marmier, autor francês, praticamente desconhecido da literatura infantil brasileira, embora tenha sido fonte da adaptação de Figueiredo Pimentel para muitos de seus textos reunidos em Contos da carochinha, obra publicada em 1894, inaugurando cronologicamente a literatura infantil brasileira, compondo a coleção Biblioteca Infantil da Livraria Quaresma.

Demonstramos, também, indícios preliminares que nos levaram a desenvolver um estudo comparativo, em busca da verificação de L'Arbre de Noël, de Xavier Marmier, como texto de partida do autor brasileiro. Como demonstramos, dos 44 (quarenta e quatro) títulos contidos na obra francesa, 26 (vinte e seis) foram levados por Figueiredo Pimentel para Contos da carochinha. Além disso, as gravuras de ambas as obras apresentam fortes semelhanças, uma vez que apresentam os mesmos elementos, embora posicionados de forma diversa como detalhamos anteriormente.

Como podemos perceber, a crença de que nossa literatura infantil tenha partido de textos recolhidos da tradição oral por grandes nomes, como Perrault, Jacob e Wilhelm Grimm, e Andersen, não pode ser considerada absoluta, uma vez que, nos primórdios dessa literatura, outros contistas podem ter influenciado tradutores e adaptadores conforme Xavier Marmier o fez em relação a Figueiredo Pimentel. Ante essas informações, chamamos atenção para a necessidade de novos estudos que se interessem pela investigação de fontes históricas de obras infantis brasileiras genericamente apontadas como adaptações ou traduções de obras tradicionalmente conhecidas e consagradas. 


\section{Referências}

ARROYO, Leonardo. Literatura infantil brasileira. $3^{\mathrm{a}}$ ed. São Paulo: Editora UNESP, 2011.

QUARESMA, Pedro. Prefácio da Primeira Edição. In: PIMENTEL, Figueiredo. Contos da avòzinha. Livraria Quaresma: Rio de Janeiro, [1896] /1959.

QUARESMA, Pedro. Prefácio. In: PIMENTEL, Figueiredo. Contos da carochinha. Livraria Quaresma: Rio de Janeiro, [1894] /1958.

Jornal do Brasil. Rio de Janeiro. 1890-2019. Disponíveis em: <http://bndigital.bn.gov.br/ hemeroteca-digital/>. Acesso em: 04 mai. 2019.

Jornal do Commercio. Rio de Janeiro. 1820-2019. Disponíveis em: <http://bndigital.bn.gov. br/hemeroteca-digital/>. Acesso em: 04 mai. 2019.

JUNQUEIRO, Guerra. Contos para a infância. Porto: Lello \& Irmão editores, [1877] /1978.

MARMIER, Xavier. L'arbre de Noël: contes et légendes recueillis par X. Marmier, 12ª ed. Paris: Librarie Hachette et Cie, 1873.

PIMENTEL, Figueiredo. Contos da carochinha. 25ª ed. Rio de Janeiro: Editora Quaresma, [1894] /1958.

ZILBERMAN, Regina. Leituras para a infância no século XIX brasileiro. Revista Fronteiraz, n. 17, 2016, p. 22-42. Disponível em: https://revistas.pucsp.br/index.php/fronteiraz/article/ view/29413. Acesso em: 26 jun. 2018. 